\title{
Synthesis and photocurrent density-photovoltage $(J-V)$ characterization of a novel alizarin derivative dye for dye-sensitized solar cell technology
}

\author{
Ismail Abubakari ${ }^{1}$ D $\cdot$ Numbury Surendra Babu ${ }^{1} \cdot$ Said Vuai $^{1} \cdot$ John Makangara ${ }^{1}$
}

Received: 28 September 2021 / Accepted: 27 November 2021 / Published online: 9 February 2022

(c) The Author(s), under exclusive licence to Islamic Azad University 2022

\begin{abstract}
Dye-sensitized solar cells technology has attracted extensive academic scholars' interests due to their potential low-cost solar energy harvesting. Increasing performance of dye-sensitized solar cell needs more efficient dye to maximize solar energy absorption. This work presents the synthesis and $J-V$ characterization studies for a novel alizarin derivative dye HDD. The dye was formed by the reaction between brominated alizarin and 5-hexyl-2-thiopheneboronic acid pinacol ester. The final dye product was successfully synthesized as brownish-orange solid. Characterization of the synthesized dye was done using spectroscopic techniques; mass spectrometry, infrared spectroscopy and nuclear magnetic resonance before photovoltaic performance investigation. The dye was found to be useful as photo-sensitizer in dye-sensitized solar cell through calculation of conversion efficiency. Generally, the dye HDD showed better results in terms of photovoltaic properties with open-circuit voltage, short-circuit current density and fill factor of $0.65 \mathrm{~V}, 0.0146 \mathrm{~A} / \mathrm{cm}^{2}$ and 0.612 , respectively. The conversion efficiency of the cell using the synthesized dye HDD was found to be $5.81 \%$ under $100 \mathrm{~mW} / \mathrm{cm}^{2}$ solar illuminations.
\end{abstract}

keywords Dye-sensitized solar cell $\cdot$ Photovoltaic properties $\cdot$ Photo-sensitizer $\cdot$ Photocurrent density $\cdot$ Photovoltage

\section{Introduction}

The unsustainability and future expected depletion of the current energy sources in form of fossil fuels and coal has strongly attracted researchers toward alternative energy sources including solar energy [1,2]. In addition to being limited, the current energy sources are non-renewable and unfortunately mostly polluting in nature [3, 4]. Additionally, the global energy demand has increased and expected to increase more as a result of growth in population while the current energy sources are fast diminishing [5]. The focus to seek for alternative energy sources come from the fact that there are plenty of renewable and unlimited energy sources including wind energy, biomass energy and solar energy which is currently the promising source [6]. As a matter of

Ismail Abubakari

ismail.msangi2@udom.ac.tz

1 Department of Chemistry, College of Natural and Mathematical Sciences, The University of Dodoma, Dodoma, United Republic of Tanzania fact, the harvesting of solar energy as an alternative to fossil and coal is inevitable.

The conventional photovoltaic of Si-based, thin films and the recent dye-sensitized solar cells (DSSCs) reported to be among the best solar energy harvesting technologies [7, 8]. The DSSCs reported to be the best performer among other technologies due to its comprehending easy fabrication technique, low production cost and its materials abundance [9, 10]. Several studies have been done on improving conversion efficiency of the DSSCs and reporting over 14.3\% [11, 12]. Up to now the struggle toward the enhancement of DSSCs is mostly based on discovery of new materials which may improve the stability and conversion efficiency and lower the cost of production $[13,14]$. The materials may be for any component of the cell whether counter-electrode, electrolyte, semiconductor or dye sensitizer [15]. To come up with more efficient cell, the solar radiation capture has to be increased, hence more studies on dye sensitizers which will maximize solar radiation harvesting up to near infrared are needed. Currently, reports show the harvesting of solar radiation by DSSCs to be about $290-800 \mathrm{~nm}$ which signifies that only a small fraction of solar energy are utilized [4]. The conjugated materials have been reported to be one of the 
solution to maximize solar energy absorption in DSSCs due to specific properties attributed by its electron delocalization abilities [16, 17]. Moreover, the conjugated molecules are non-amorphous, easy to synthesize and display decent relationship between donor and acceptor groups in relation to photovoltaic performance $[18,19]$.

Structurally, DSSC consists of electrolyte, photo-electrode adsorbed with a dye and semiconductor and counterelectrode adsorbed with conductive grade, each with its unique role [20]. Among the components, dye sensitizer is reported to play a primary role in DSSCs as a source of electrons to the conduction band upon photo-excitation [21]. Since its discovery by Grätzel's group [7], several other researches have been conducted to sightsee the unique replacements for dye sensitizer, electrolyte and electrodes for efficiency improvement of DSSCs [11, 22]. A number of components has been reported including Pt-based and carbon-based counter-electrode, $\mathrm{TiO}_{2}$ and $\mathrm{ZnO}$ semiconductors and iodine-based electrolyte [23, 24].

The dye sensitizers as among the component in DSSCs may range from natural [25] to synthetic and the synthetic may either be metal-free [26, 27] or metal-containing [28]. Several dye molecules useful in DSSCs with pronounced charge carrier mobility and excellent stability have been reported so far [29, 30]. Among of several reported dyes is alizarin reaching up to $3.57 \%$ using untreated semiconductor and 5.12\% using treated semiconductor [31]. Alizarin molecule is among the oldest dye in dye industries formerly used in dying fabrics in textile industries and in biological researches as staining agent [32]. Obviously, alizarin is a natural dye extracted from the roots of madder plant. Though alizarin dye is known past 6000 years, it was successfully isolated at first from the roots of madder in 1826 and become the first natural dye to be duplicated synthetically in 1869 $[33,34]$. Despite its age in dye technology, alizarin derivative studies were not often reported. Recently, a theoretical study on alizarin through substitution of its hydroxyl groups by conjugated molecules containing thiophene, benzene, and thieno[3,2-b]thiophene has been reported [35]. Not only that but also in our previous works we reported the theoretical study on substitution of alizarin molecule through its hydrogen atoms using 4-(benzo[c][1,2,5]thiadiazol-4-yl) benzoic acid, 2-hexylthiophene and carboxylic acid [4, 36] where several dye molecules were argued to be useful in DSSCs application. Taking into consideration the several modification possibilities in alizarin through its hydroxyl groups, carbonyl groups and several attached hydrogen atoms, concentrating into studies on this molecule may result to a dye molecule which will go beyond pure alizarin in DSSC technology. The few reported theoretical studies on derivative of alizarin have ended up with convincing outputs which arouse the mind set to think about its practical applicability hence a need for experimental studies on the same. Therefore this work reports the synthesis of one of the theoretically reported alizarin derivative dye [36] and its applicability in DSSCs technology. The reported dye molecule may be among the succession to the commercialization of DSSC which will reduce the crisis of power especially in rural areas of developing countries where the supply from national grid is still questionable.

\section{Materials and method}

\section{Materials}

Alizarin (Aldrich, USA), Bromine (Aldrich, USA), Carbon disulphide (Aldrich, USA), Deionized water, Glacial acetic acid (Finar, India), 5-Hexyl-2-thiopheneboronic acid pinacol ester (Aldrich, USA), Sodium carbonate (Finar, India), Palladium catalyst (Aldrich, USA), Hydrochloric acid (Finar, India), Ethanol (Finar, India), 2-propanol (Aldrich, USA), Acetonitrile (Finar, India), Polyethylene glycol-PEG (Finar India), Iodine- $\mathrm{I}_{2}$ (Aldrich, USA), Lithium iodide-LiI (Aldrich, USA), Polyethylenedioxythiophene:polystyrene sulphonate-PEDOT:PSS (Clevios, Germany), Single-walled carbon nanotubes-SWCNT (Carbonium, Italy), Transparent Titanium oxide paste- $\mathrm{TiO}_{2}$ paste (Solaronix, Switzerland), Fluorine-doped tin oxide (FTO) glass substrate (Solaronix, Switzerland). All materials were of analytical grade hence used in this study without any further purification.

\section{Synthesis of molecular dye, HDD}

The molecular dye HDD presented in Fig. 1 was synthesized using two main precursors, brominated alizarin and 5-hexyl2-thiopheneboronic acid pinacol ester. Unfortunately, the precursor brominated alizarin was not commercially available hence it was also synthesized in this study. The synthesized brominated alizarin molecule was given the label BA and presented in Fig. 2.

\section{Synthesis of the precursor BA}

Brominated alizarin (BA) was obtained by heating the mixture of $2.5 \mathrm{~g}$ of bromine and $3 \mathrm{~g}$ of alizarin in carbon disulphide using a thermal reactor to $190{ }^{\circ} \mathrm{C}$ for $5 \mathrm{~h}$. After $5 \mathrm{~h}$ of reaction, the thermal reactor was carefully opened and allowed the gases in the reactor to escape. As soon as the excess gases escaped, the product was transferred to a shallow dish and excess gases were allowed to evaporate. The obtained product was washed by deionized water and then filtered by vacuum filtration. The product was left to dry on filter paper for about $20 \mathrm{~min}$. The partially dried product was then transferred into a beaker and purified by crystallization using glacial acetic acid. The crystals were filtered 


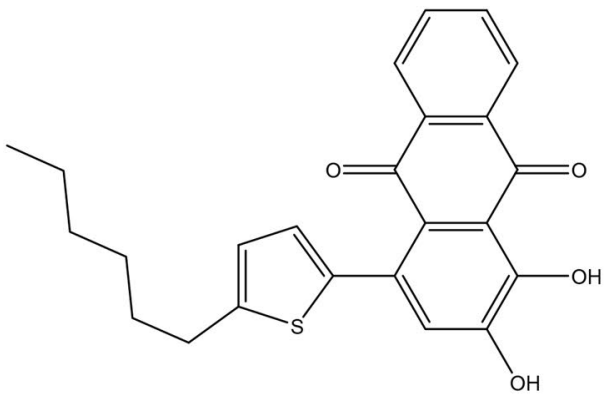

$\mathbf{a}$

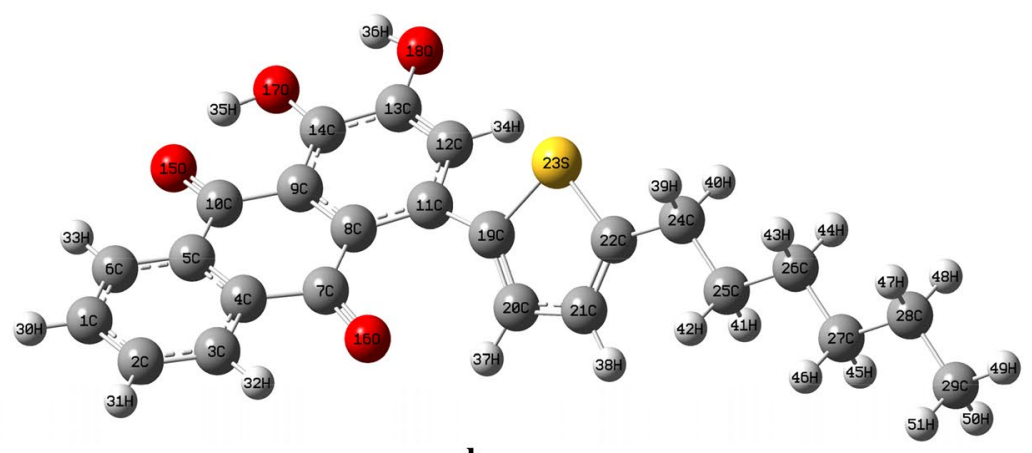

b

Fig. 1 The HDD dye molecule under experimental study $\mathbf{a}$ before optimization $\mathbf{b}$ after optimization<smiles>O=C1c2ccccc2C(=O)c2c1cc(O)c(O)c2Br</smiles>

$\mathbf{a}$

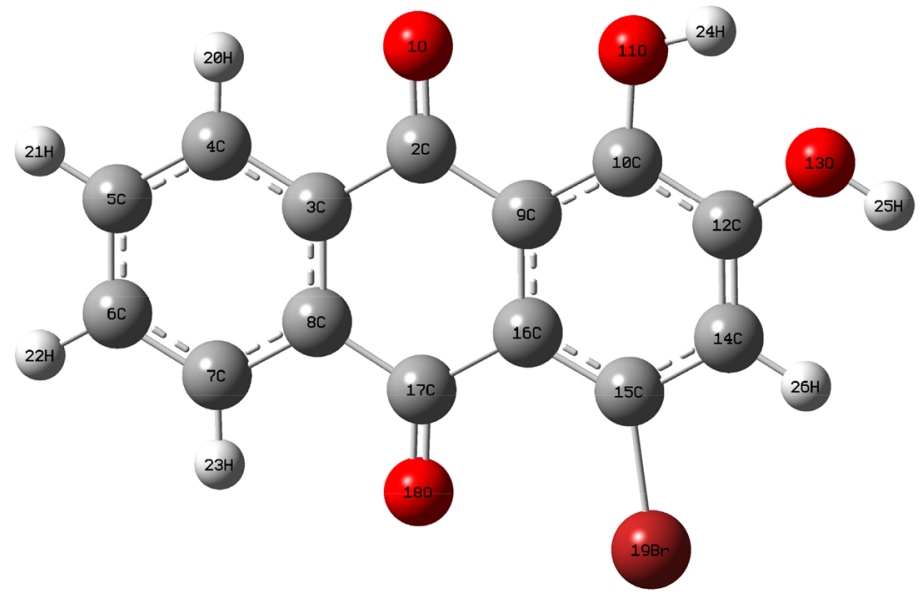

b

Fig. 2 The synthesized precursor bromalizarin BA $\mathbf{a}$ before optimization $\mathbf{b}$ after optimization

by vacuum filtration and a small amount of acetic acid was used to rinse the product out of the flask. The crystals were dried over the filter paper to obtain the final product, BA.

\section{Synthesis of the final dye molecule HDD}

In a $125 \mathrm{ml}$ reaction flask containing a stirring bar, $0.50 \mathrm{~g}$ of BA and $0.37 \mathrm{~g}$ of 5-hexyl-2-thiopheneboronic acid pinacol ester were mixed. In a separate reaction flask, $0.80 \mathrm{~g}$ of sodium carbonate and $15 \mathrm{ml}$ of deionized water were mixed and stirred until the mixture dissolved completely. Thereafter, the contents in flasks 1 and 2 were mixed together and stirred vigorously. The obtained resulting solution was then heated to $70{ }^{\circ} \mathrm{C}$ followed by addition of few drops of $0.25 \mathrm{mM}$ palladium catalyst solution and allowed to run for $30 \mathrm{~min}$ at $70{ }^{\circ} \mathrm{C}$ while stirred vigorously. The solution was then cooled to room temperature and placed in an ice bath while still stirred effectively. A portion of $25 \mathrm{ml}$ of $1 \mathrm{M}$ hydrochloric acid $(\mathrm{HCl})$ were added slowly directly into the flask and continue stirred for 5 min after full addition. Then the obtained crude product was isolated by vacuum filtration, rinsed by deionized water and left to dry on filter paper for $20 \mathrm{~min}$. The partially dried product was transferred into a beaker and purified by crystallization using ethanol. The crystalline product was then isolated by vacuum filtration, rinsed by ethanol and dried on filter paper to obtain the final product, HDD.

\section{Characterization of synthesized molecules, BA and HDD}

The synthesized molecules were characterized by using different spectroscopic techniques, infrared spectroscopy (IR), nuclear magnetic resonance (NMR) and mass spectrometry (MS). Multi-scanning Agilent LCMS (USA) was used for mass spectrometry. To check different functional groups and distortion of the molecular structure, JASCO FT-IR spectrometer (USA) was used to perform IR spectrometry. 
Moreover, the structural elucidation was done using the AVANCE Neo, $400 \mathrm{MHz}$ (Germany) for both ${ }^{1} \mathrm{H}$ NMR and ${ }^{13} \mathrm{C}$ NMR spectroscopy.

\section{Preparation of counter-electrode (CE)}

The FTO glass substrate was cleaned and rinsed with deionized water and 2-propanol then sonicated in deionised water for $15 \mathrm{~min}$ and in propanol for $1 \mathrm{~h}$. The glass was then drilled using a diamond-tipped micro drill bit (DREMEL 300) to make a hole for injecting the electrolyte then washed again with deionized water and 2-propanol. Thereafter the glass was coated with PEDOT:PSS using spin coating technique. The PEDOT:PSS coated FTO glass was then heated at $170{ }^{\circ} \mathrm{C}$ for 30 min then coated with $1 \mathrm{mg}$ SWCNT in $10 \mathrm{ml}$ of 2-propanol using the same technique. The glass was heated again at $170{ }^{\circ} \mathrm{C}$ for $30 \mathrm{~min}$ to obtain the counter-electrode.

\section{Preparation of photo-electrode (PE)}

The FTO glass substrate was cleaned, sonicated and then dried under $\mathrm{N}_{2}$ purge. The $\mathrm{TiO}_{2}$ paste prepared using ethanol was coated over the dried FTO glass by spin coating technique and then heated to $500{ }^{\circ} \mathrm{C}$ for $30 \mathrm{~min}$. The sintered $\mathrm{TiO}_{2}$-coated FTO glass was dipped in the solution of synthesized dye HDD and left for $18 \mathrm{~h}$ for sensitization under dark condition. The sensitized glass substrate was rinsed by ethanol to remove unattached dyes and dried under $\mathrm{N}_{2}$ purge to form the photo-electrode.

\section{Preparation of electrolyte}

The electrolyte $\left(I^{-} / I_{3}^{-}\right)$was prepared by taking a proportionate quantity of $0.5 \mathrm{~mol}$ potassium iodide (KI), $0.05 \mathrm{~mol}$ of iodine and $0.14 \mathrm{~mol}$ of polyethylene glycol (PEG) of molecular weight $400 \mathrm{~g} / \mathrm{mol}$ in $50 \mathrm{ml}$ of acetonitrile solvent.

\section{Fabrication of DSSC model}

The DSSC model for characterization was made by sandwiching the counter-electrode and photo-electrode using polymer melts film and then slightly pressed over hot plate for binding. The use of polymer was just for creating a space between the two electrodes for injection of electrolyte. After packing of electrodes, the electrolyte was injected through the drilled hole on counter-electrode and finally the hole was sealed to obtain DSSC. The schematic diagram to illustrate the structure of fabricated DSSC model is presented in Fig. 3.

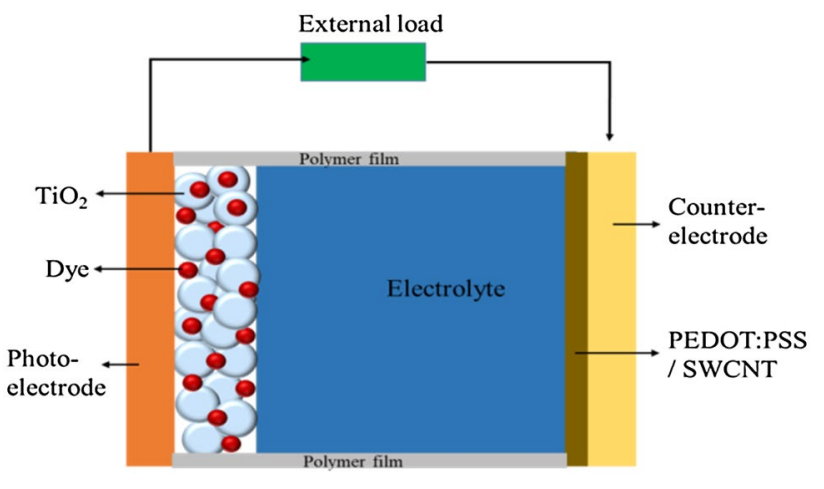

Fig. 3 The schematic diagram of fabricated DSSC model for testing

\section{Characterization of DSSC}

Characterization of the fabricated cell was done using the photocurrent density-photovoltage $(J-V)$ characteristics. The $J-V$ characteristics of the fabricated DSSC model was recorded using a solar simulator PEC-L01 (PECCELL Inc., Japan) and its light intensity was adjusted to $100 \mathrm{mWcm}^{-2}$ sun light condition using calibrated Si-based standard solar cell. Through the $J-V$ curve, short-circuit current density $\left(J_{\mathrm{sc}}\right)$, open-circuit voltage $\left(V_{\mathrm{oc}}\right)$ and fill factor $(\mathrm{FF})$ were obtained and finally conversion efficiency $(\eta)$ was obtained using Eq. 1.

$\eta=\frac{\mathrm{FF} \times J_{\mathrm{sc}} \times V_{\mathrm{oc}}}{P_{\mathrm{in}}}$

\section{Results and discussion}

\section{Synthesis of BA and HDD}

The precursor BA was successfully synthesized as orange solids which were crystallized to form orange-coloured needle like solids as presented in Fig. $4 \mathrm{a}$ and $\mathrm{b}$. The final dye molecule HDD was synthesized as brownish orange solids as seen in Fig. 4c and d. After synthesis the materials were subject to characterization to confirm the final products.

\section{Mass spectrometry studies}

The mass spectrum (MS) of the first synthesized molecule BA is as presented in Fig. 5a. The MS of BA revealed the molecular formular to be $\mathrm{C}_{14} \mathrm{H}_{7} \mathrm{BrO}_{4}$ which corresponds to the molecular weight $318.9 \mathrm{~g} / \mathrm{mol}$. The MS of BA in Fig. 5a shows different fragments including the one at $\mathrm{m} / \mathrm{z} 318.02$. This peak at $\mathrm{m} / \mathrm{z} 318.02$ was assigned to the mass of the 
Fig. 4 The synthesized molecules a BA before crystallization b BA after crystallization c HDD before crystallization d HDD after crystallization

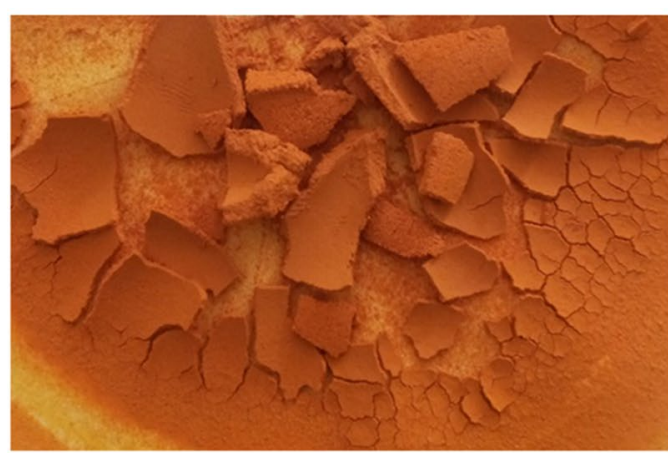

$\mathbf{a}$

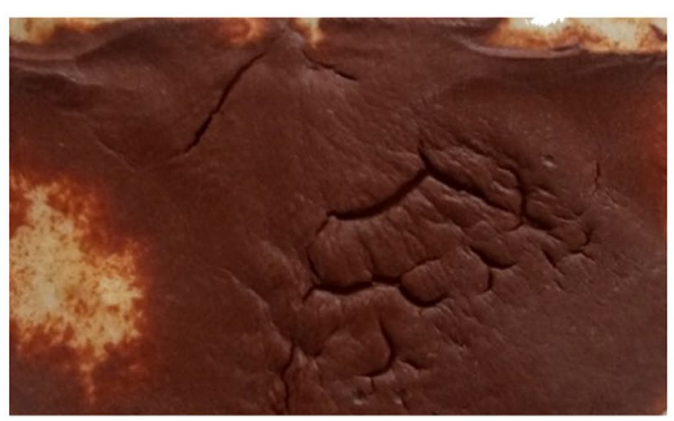

c

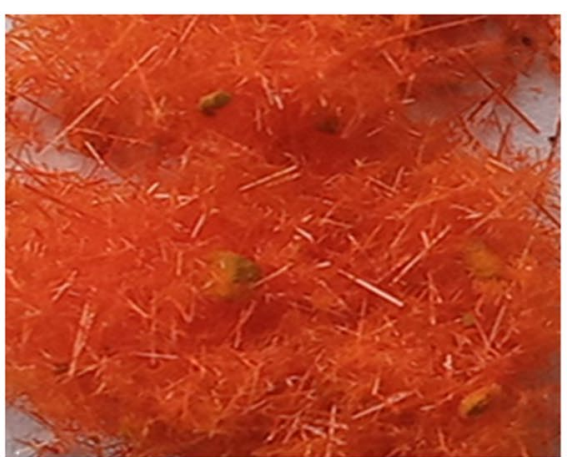

b

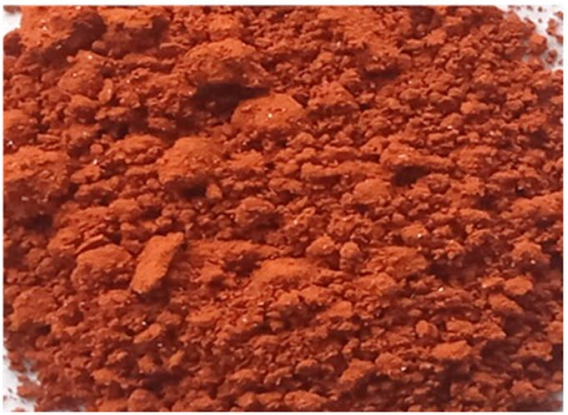

d synthesized molecule BA and signifies the successful synthesis of the targeted molecule. The MS of the second synthesized dye molecule HDD is as presented in Fig. 5b. The molecular formular of this dye was revealed by MS to be $\mathrm{C}_{24} \mathrm{H}_{22} \mathrm{O}_{4} \mathrm{~S}$ corresponding to molecular weight of $406.5 \mathrm{~g} /$ mol. As witnessed from Fig. 5b, different fragments were analyzed to come from HDD and the one at $\mathrm{m} / \mathrm{z} 406.02$ correspond to the dye molecule HDD and confirms the successful synthesis of the intended dye. Several other peaks due to fragmentation were also observed in the MS of HDD.

\section{Infrared spectroscopy studies}

The IR spectrum for BA is as presented in Fig. 6a. The spectrum was used to analyze the important functional groups present in a molecule to justify non-destruction of crucial groups. For more clarification, the IR spectrum of pure alizarin was also considered due to the fact that the only difference between BA and alizarin is attachment of bromine in BA instead of $\mathrm{H}$ atom in alizarin. The reference IR data were retrieved from the spectral database for organic compounds, SDBS [37]. The important selected IR peaks for both BA and alizarin are as presented in Table 1 for comparison.

The typical absorption broad band at $3391.15 \mathrm{~cm}^{-1}$ corresponds to $\mathrm{OH}$ vibration of $\mathrm{BA}$ and justifies the nondestruction of the $\mathrm{OH}$ groups during synthesis. The bromine attachment succession in BA was defensible by presence of its possible peak in finger print region at $645.36 \mathrm{~cm}^{-1}$ [38]. The peak at $1661.55 \mathrm{~cm}^{-1}$ was assigned to carbonyl group
$(\mathrm{C}=\mathrm{O})$ vibrations while that at 1631.02 and $1588.78 \mathrm{~cm}^{-1}$ were corresponding to $\mathrm{C}=\mathrm{C}$ vibrations from the two different side rings of alizarin molecule. The observed signal from $\mathrm{C}=\mathrm{O}$ and $\mathrm{C}=\mathrm{C}$ explain also the non-destruction of the carbonyl group and the aromatic rings during synthesis of BA. The little shift of carbonyl group to 1661.55 was argued to be due to high conjugation in BA molecule. These three important peaks are also observed in reference IR spectrum of alizarin from SDBS [37]. The other peaks in finger print region observed in $\mathrm{BA}$ were also witnessed in reference IR spectrum of alizarin except the peak at $645.36 \mathrm{~cm}^{-1}$ which was assigned to $\mathrm{C}-\mathrm{Br}$ vibrations.

The IR spectrum of the synthesized final dye HDD is as presented in Fig. 6b. Generally, HDD composed of alizarin and 2-hexylthiophene moieties joined together through substitution of $\mathrm{Br}$ atom of BA by the 2-hexylthiophene from 5-Hexyl-2-thiopheneboronic acid pinacol ester. The IR spectrum of HDD displayed three important peaks at $2979.67,2928.41$ and $2856.22 \mathrm{~cm}^{-1}$. These peaks correspond to saturated $\mathrm{C}-\mathrm{H}$ stretching from the hexyl group of 2-hexylthiophene. Worth to note that the IR spectrum of BA display no peak around this region hence confirmed to come from the other precursor 2-hexylthiophene. The peaks were also displayed in the IR spectrum of 2-hexylthiopehe at 2956, 2928 and $2856 \mathrm{~cm}^{-1}$, respectively, as obtained from the SDBS [39]. The HDD IR peak at $1473.77 \mathrm{~cm}^{-1}$ corresponds to peak at $1439 \mathrm{~cm}^{-1}$ of BA while the HDD peak at $1455.58 \mathrm{~cm}^{-1}$ corresponds to 


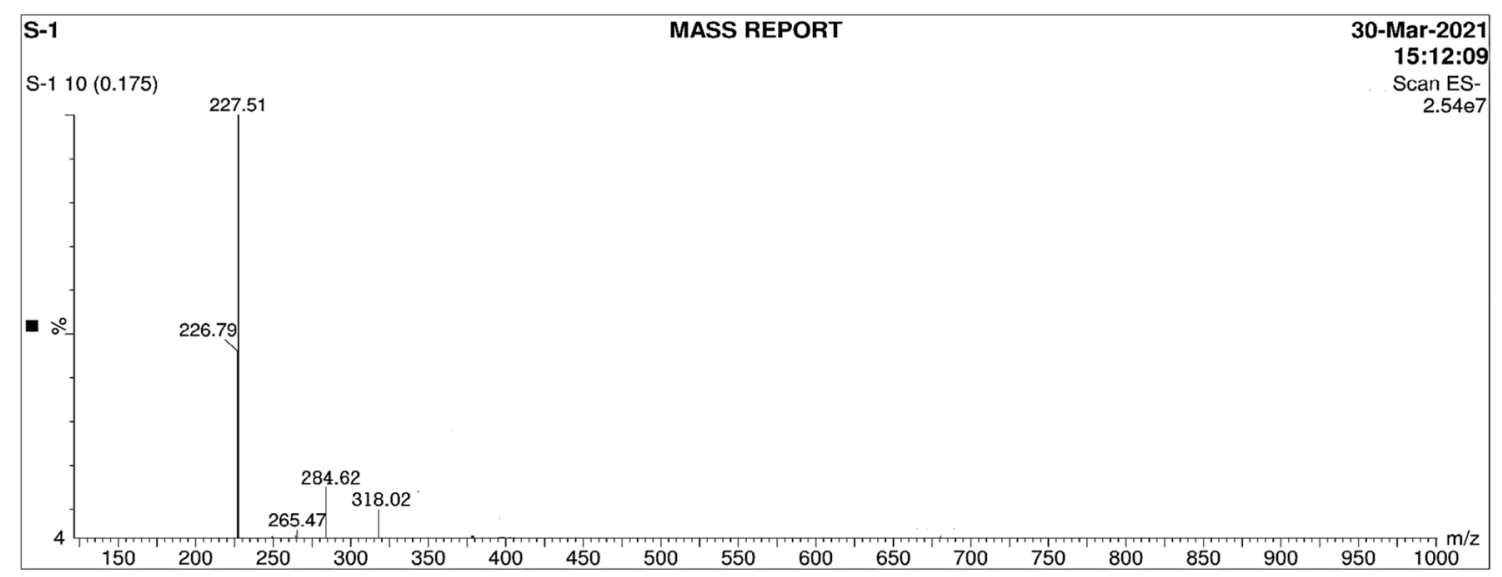

$\mathbf{a}$

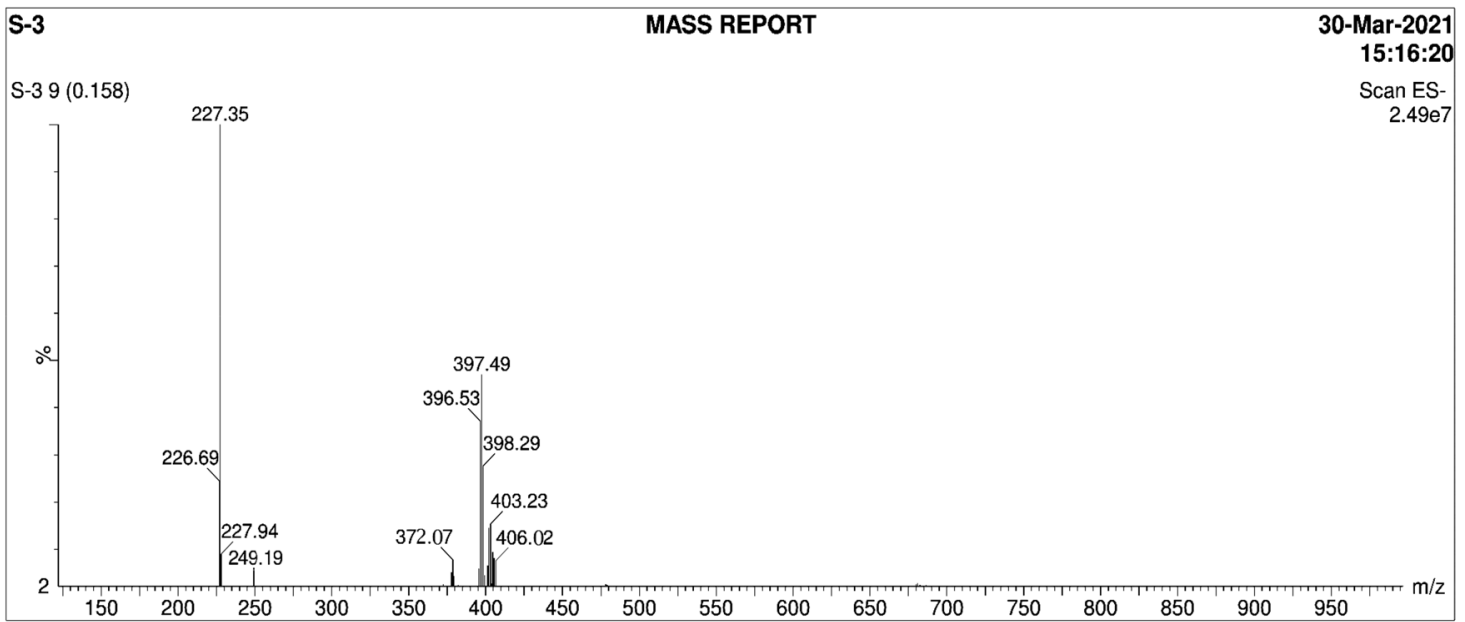

b

Fig. 5 The mass spectra of synthesized molecules a BA b HDD

peak at $1441 \mathrm{~cm}^{-1}$ of the 2-hexylthiophene. Among other peaks, the IR spectrum of BA showed an important peak at $1296.19 \mathrm{~cm}^{-1}$ which appears also in the IR spectrum of HDD at $1291.07 \mathrm{~cm}^{-1}$ while the IR spectrum of 2-hexylthiophene shows a peak at $1258.00 \mathrm{~cm}^{-1}$ which appears also in the IR spectrum of HDD at $1256.72 \mathrm{~cm}^{-1}$. The peak at $645.26 \mathrm{~cm}^{-1}$ which was due to $\mathrm{C}-\mathrm{Br}$ vibration in BA precursor disappeared in the IR spectrum of the final product HDD. This is due to the fact that bromine of BA was replaced by the 2-hexylthiophene to form a C-C bond which joined alizarin and 2-hexylthiophene moieties. Several peaks in IR spectrum of HDD were observed to come from both precursors BA and 2-hexylthiophene hence justifies the success in the synthesis of the final dye HDD. Table 2 shows some important selected IR signals of the final dye HDD and its two precursors BA and 2-hexylthiophene.

\section{${ }^{1}$ H NMR spectroscopy studies}

The ${ }^{1} \mathrm{H}$ NMR spectral data of the synthesized precursor BA are presented in Fig. 8a. It should be noted that the formed product $\mathrm{BA}$ is a result of substitution of $\mathrm{H}$ by bromine from alizarin. The ${ }^{1} \mathrm{H}$ NMR in that case will help to verify which proton has been replaced by the bromine. The ${ }^{1} \mathrm{H}$ NMR spectrum of BA exhibited signals that were consistent with that of alizarin with one exception. The signal of a proton at $\delta 7.598 \mathrm{ppm}$ revealed in alizarin [40] was missing in the ${ }^{1} \mathrm{H}$ NMR spectrum of BA. This tells that the proton at $\delta$ $7.598 \mathrm{ppm}$ in alizarin was replaced by the incoming bromine. The missing proton was assigned letter $D$ in alizarin in reference data which corresponds to the attachment at C-15 in BA as it can be observed from Fig. 1b. This justifies the attachment of bromine at $\mathrm{C}-15$ during the formation of the brominated alizarin in Fig. 1b, hence successful formation of BA. The simplified information on attachment of bromine is 
Fig. 6 The IR spectra of synthesized molecules a BA b HDD

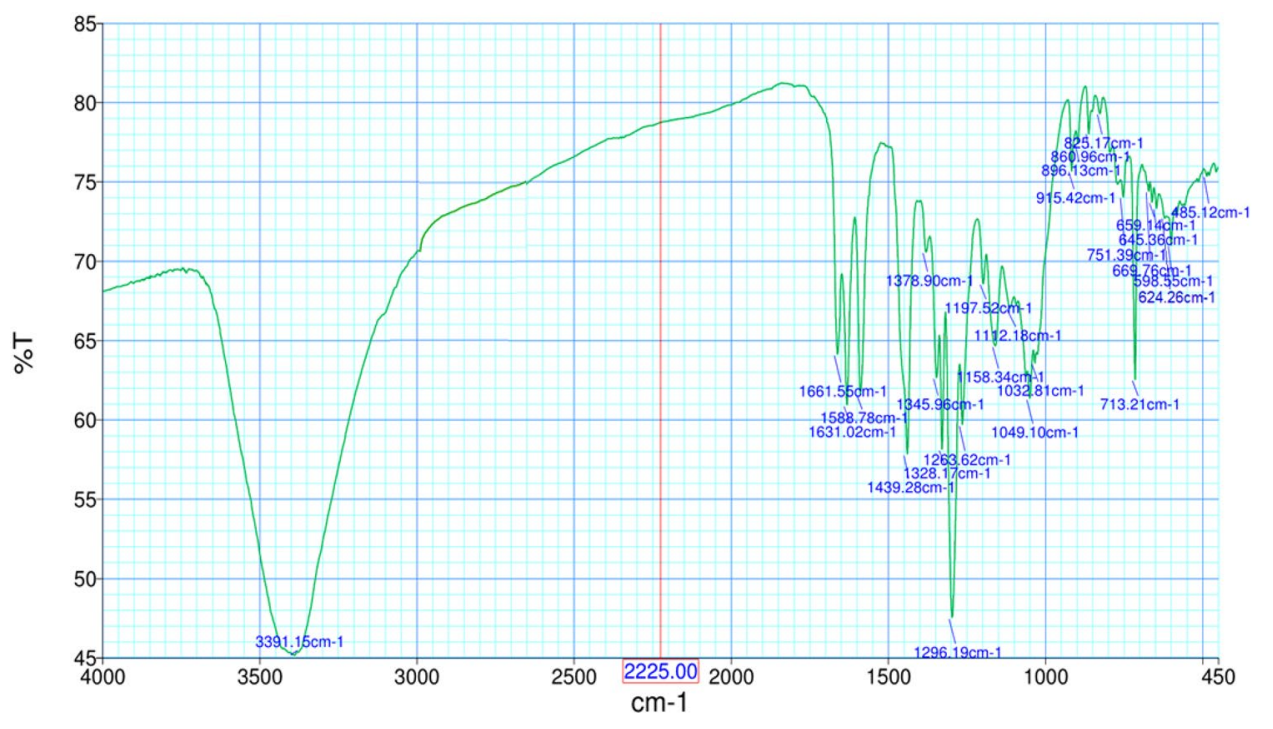

a

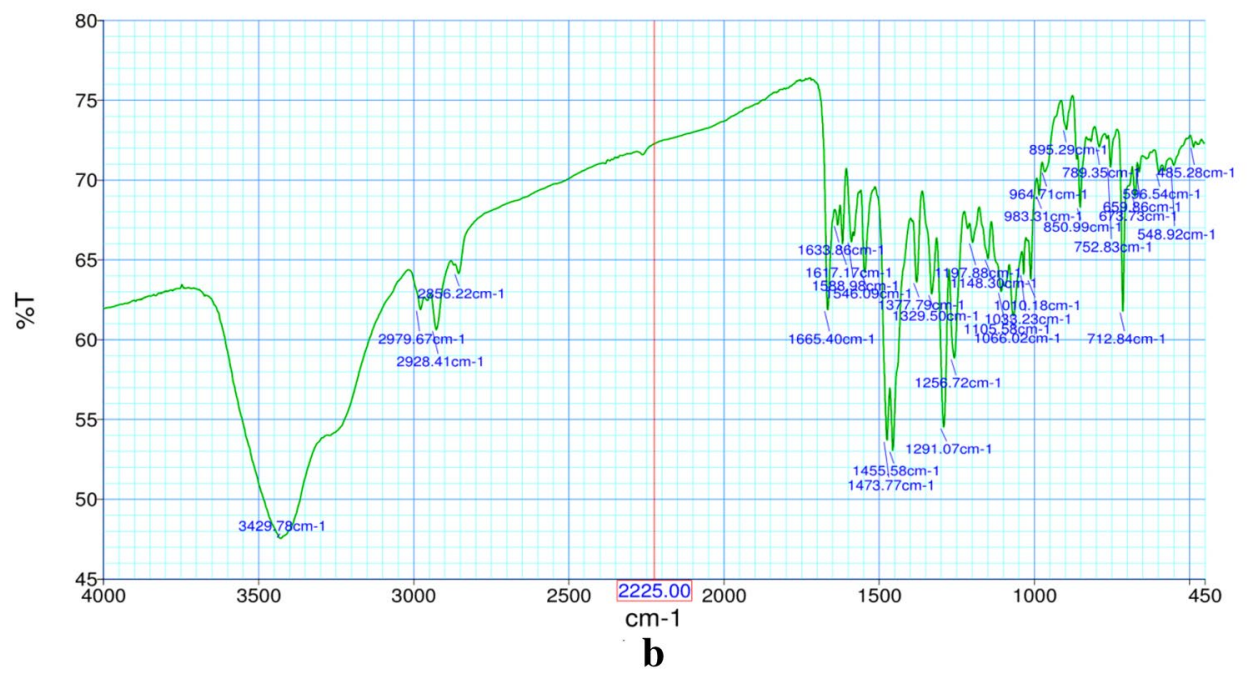

Table 1 The selected IR spectral data for BA and alizarin molecule

\begin{tabular}{lllll}
\hline \multicolumn{2}{l}{ Wavenumber $\left(\mathrm{cm}^{-1}\right)$} & & \multicolumn{2}{l}{ Transmittance $(\% \mathrm{~T})$} \\
\cline { 5 - 5 } \cline { 5 - 5 } BA & Pure alizarin & & BA & Pure alizarin \\
\hline 3391.15 & 3426.00 & & 45.1 & 37.0 \\
1661.55 & 1664.00 & & 64.1 & 27.0 \\
1631.02 & 1634.00 & & 61.0 & 27.0 \\
1588.78 & 1589.00 & & 62.5 & 23.0 \\
645.36 & & 73.4 & \\
\hline
\end{tabular}

presented in Table 3 . The proton labeling of BA and alizarin as from the database is shown in Figs. 7a and b, respectively.

All other proton signals of alizarin molecule, $\delta 8.158$, 8.109, 7.860 and 7.194 ppm displayed also in ${ }^{1} \mathrm{H}$ NMR spectrum of BA, $\delta 8.230,8.169,7.941$ and 7.235 ppm, respectively. Moreover, the signal between $\delta 7.235 \mathrm{ppm}$ and $\delta$ $8.230 \mathrm{ppm}$ in the ${ }^{1} \mathrm{H}$ NMR spectrum of BA showed that the protons were aromatic, hence non-destruction of aromatic rings of alizarin during synthesis. As observed in Table 3, all proton signals in the BA ${ }^{1} \mathrm{H}$ NMR spectrum appeared downfield compared with that of pure alizarin. This was due to the attachment of more electronegative substituent, bromine, to alizarin molecule. As an electronegative substituent, bromine deshielded the proton attached to the BA molecule by withdrawing electrons from around the protons. Decreasing in electron density reduces the induced magnetic field and as a result it lowers the strength of the magnetic field which is required to bring protons into resonance at a fixed frequency. Therefore, the deshielded protons show the signals at lower field in in the ${ }^{1} \mathrm{H}$ NMR spectrum [38].

Another discussed ${ }^{1} \mathrm{H}$ NMR was of the final dye HDD. Generally, the final dye HDD is the combination of BA and 2-hexylthiophene with the removal of $\mathrm{Br}$ and $\mathrm{H}$, respectively. The ${ }^{1} \mathrm{H}$ NMR spectrum of HDD is as presented in Fig. 8b and summarized in Table 4 . From the ${ }^{1} \mathrm{H}$ NMR spectrum 
Table 2 The selected IR spectral data for final dye HDD and its precursors BA and 2-hexylthiophene

\begin{tabular}{|c|c|c|c|}
\hline $\operatorname{HDD}\left(\mathrm{cm}^{-1}\right)$ & $\mathrm{BA}\left(\mathrm{cm}^{-1}\right)$ & $\begin{array}{l}\text { 2-hexylthiophene } \\
\left(\mathrm{cm}^{-1}\right)\end{array}$ & Signal \\
\hline 3429.78 & 3391.15 & & $\mathrm{O}-\mathrm{H}$ vibrations \\
\hline 2979.67 & & 2956 & Saturated C-H stretching from hexyl group \\
\hline 2928.41 & & 2928 & Saturated C-H stretching from hexyl group \\
\hline 2856.22 & & 2856 & Saturated $\mathrm{C}-\mathrm{H}$ stretching from hexyl group \\
\hline 1665.40 & 1661.55 & & $\mathrm{C}=\mathrm{O}$ vibrations \\
\hline 1633.86 & 1631.02 & & $\mathrm{C}=\mathrm{C}$ vibrations from alizarin side ring \\
\hline 1617.98 & 1588.78 & & $\mathrm{C}=\mathrm{C}$ vibrations from alizarin side ring \\
\hline 1588.98 & & 1580 & $\mathrm{C}=\mathrm{C}$ vibration from thiophene ring \\
\hline \multirow[t]{2}{*}{1546.09} & & 1535 & $\mathrm{C}=\mathrm{C}$ vibration from thiophene ring \\
\hline & 645.36 & & $\mathrm{C}-\mathrm{Br}$ vibrations \\
\hline
\end{tabular}

Table 3 The comparison of ${ }^{1} \mathrm{H}$ NMR assignment and its signals for BA and alizarin molecules

\begin{tabular}{lllll}
\hline \multicolumn{2}{c}{ Assignment } & & \multicolumn{2}{c}{$\delta(\mathrm{ppm})$} \\
\cline { 1 - 1 } BA & Alizarin & & BA & Alizarin \\
\hline 1 & $\mathrm{~A}$ & & 8.230 & 8.158 \\
2 & $\mathrm{~B}$ & & 8.169 & 8.109 \\
3 & $\mathrm{C}$ & & 7.941 & 7.860 \\
& $\mathrm{D}$ & & 7.598 \\
4 & $\mathrm{E}$ & & 7.235 & 7.194 \\
\hline
\end{tabular}

of HDD, all the signals revealed by the BA precursor were also revealed in molecular dye HDD. The signals at $\delta 8.230$, $8.169,7.941$ and $7.235 \mathrm{ppm}$ in BA corresponds to signals at $\delta 8.228,8.162,7.945$ and $7.034 \mathrm{ppm}$ in final dye HDD, respectively. The appearance of these signals indicates that the incoming group 2-hexylthiophene substituted bromine and not $\mathrm{H}$ atom or other groups like $\mathrm{OH}$ and $\mathrm{CO}$ as discussed also through IR spectra. The signals of HDD originated from the precursor BA appears up-field as compared with the origin BA due to the removal of more electronegative substituent bromine. Table 4 summarizes the ${ }^{1} \mathrm{H}$ NMR spectral data for final dye and the precursors. The numbering of protons for BA is as presented in Fig. 7 while that of HDD and 2-hexylthiophene is as presented in Fig. 9 [41].

The broad multiplet signal at $\delta 1.268,1.246$ and $1.226 \mathrm{ppm}$ in ${ }^{1} \mathrm{H}$ NMR spectrum of HDD corresponded to the signal at $\delta 1.360,1.320$ and $1.300 \mathrm{ppm}$ of precursor 2-hexylthiophene. The signals of these protons seem to shift up-field due to the attachment of an electron donating group, 2-hexylthiophene which increases the electron density and thus resulting into slight shielding leading to the $\delta$ values observed.

Furthermore, the signals at $\delta 0.870,1.619,2.797,6.841$ and $6.933 \mathrm{ppm}$ from HDD spectrum were in consistency to those of 2-hexylthiophene at $\delta 0.886,1.670,2.815,6.770$ and $6.905 \mathrm{ppm}$, respectively. From the database, the total of nine proton signals were displayed in ${ }^{1} \mathrm{H}$ NMR of 2-hexylthiophene as labeled in Fig. 9b. Eight signals were exhibited in the ${ }^{1} \mathrm{H}$ NMR spectrum of HDD, whereas a signal at $\delta$ $7.092 \mathrm{ppm}$ did not appear in spectrum of the final dye HDD. This observation leads to the conclusion that the proton at $\delta 7.092 \mathrm{ppm}$ from 2-hexylthiophene was substituted during the formation of the final dye HDD. The ${ }^{1} \mathrm{H}$ NMR for precursor 2-hexylthiophene was obtained from the database SDBS [41].

\section{The ${ }^{13} \mathrm{C}$ NMR spectroscopy studies}

The ${ }^{13} \mathrm{C}$ NMR spectrum of the synthesized BA is as presented in Fig. 10a. All the signals in the ${ }^{13} \mathrm{C}$ NMR spectrum of BA were consistent with those of alizarin molecule. The ${ }^{13} \mathrm{C}$ spectral data for $\mathrm{BA}$ and alizarin are as presented in Table 5 to show the comparison. The ${ }^{13} \mathrm{C}$ NMR spectral data
Fig. 7 The proton labeling of molecules a BA b alizarin [40]<smiles>O=C1c2c(O)c(O)c([Hg])c(Br)c2C(=O)c2c([Hg])c([Hg])c([Hg])c([Hg])c21</smiles>

$\mathbf{a}$

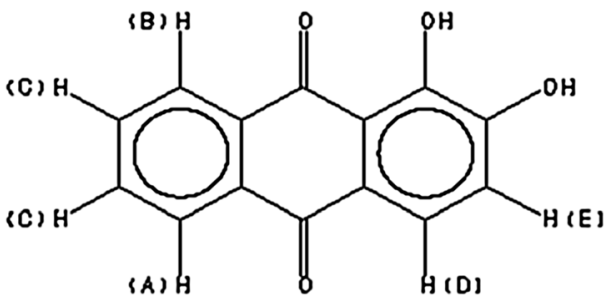

b 


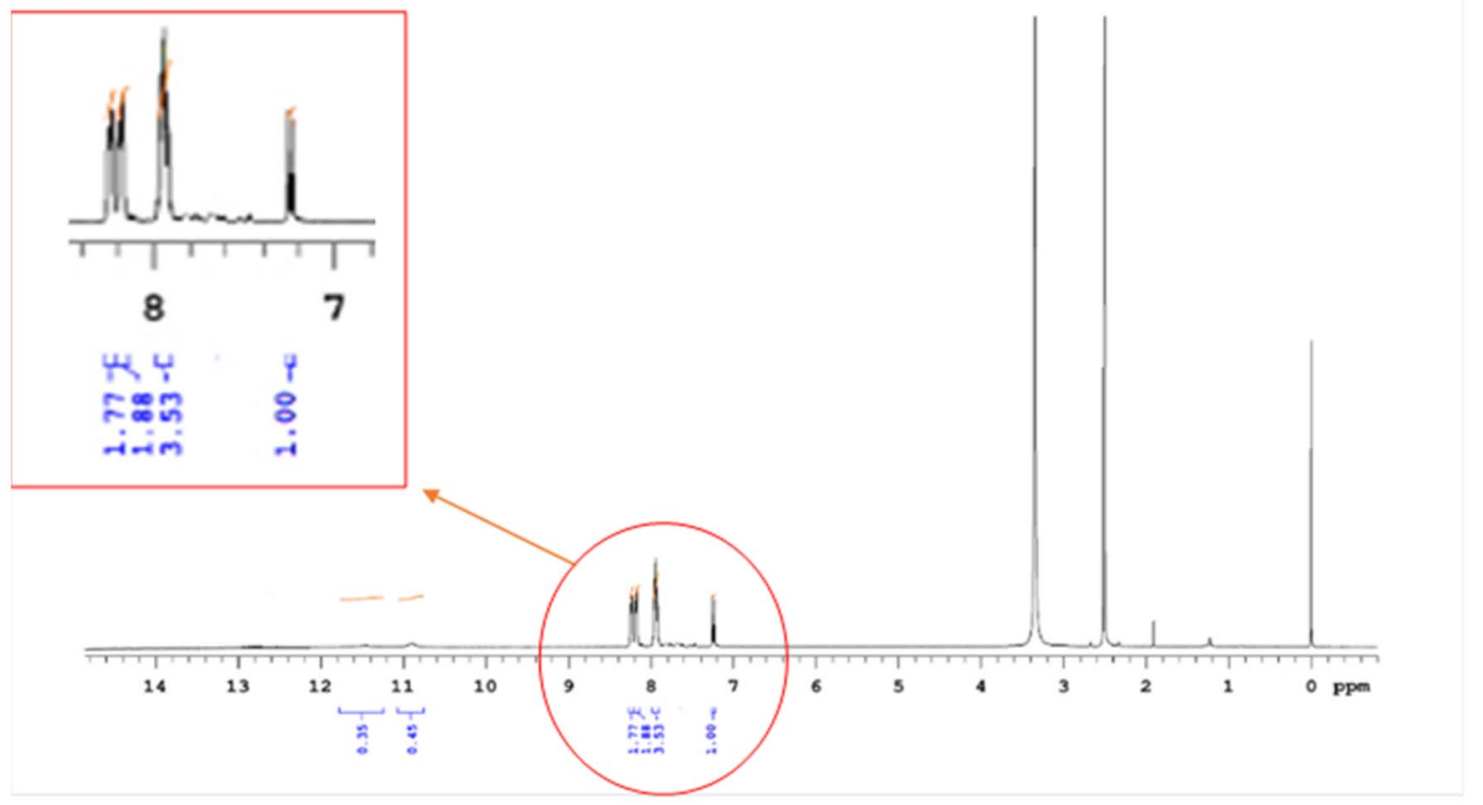

a

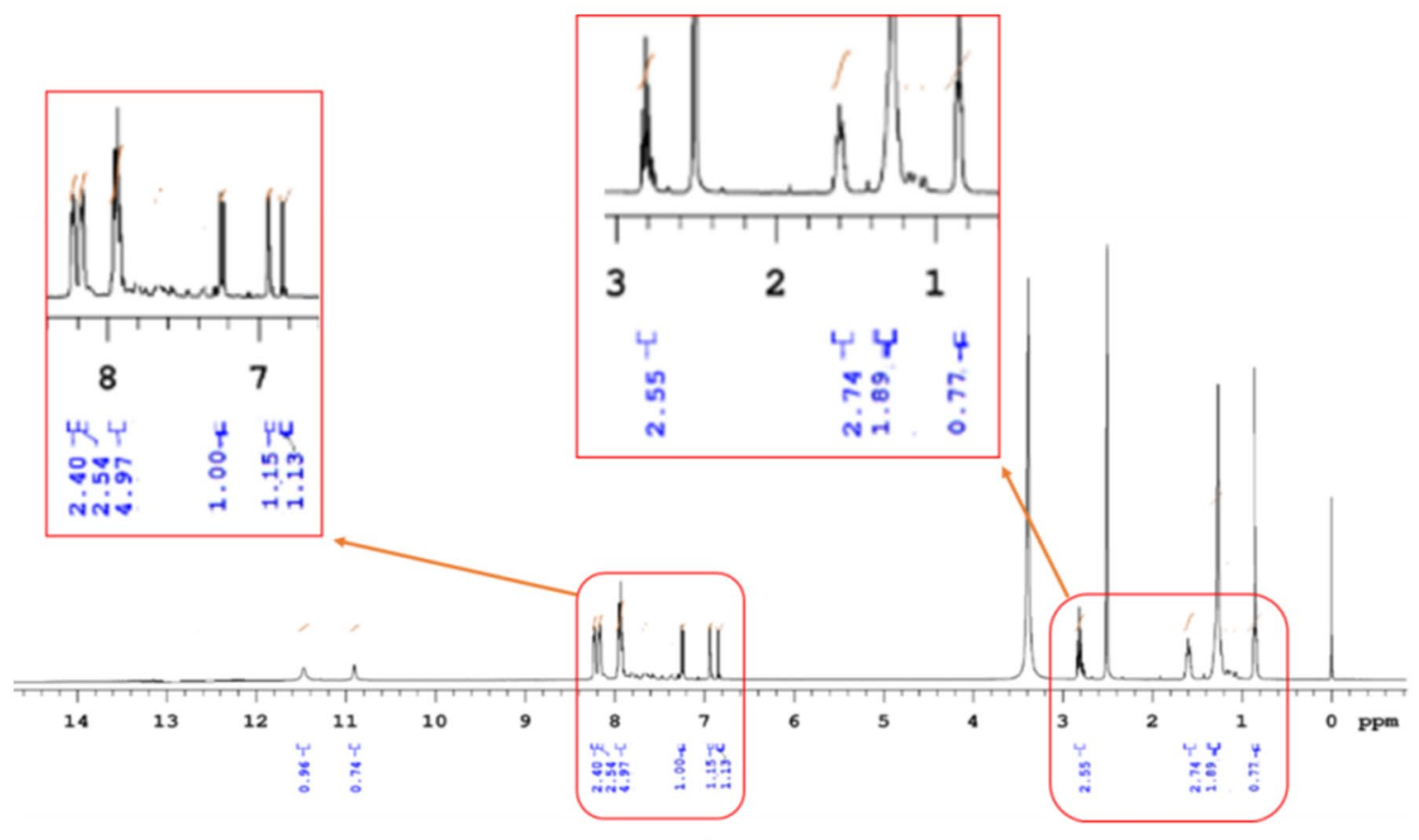

b

Fig. 8 The ${ }^{1} \mathrm{H}$ NMR of the synthesized molecules a BA b HDD

for alizarin and 2-hexylthiophene were taken from the SDBS database [40, 41].

The ${ }^{13} \mathrm{C}$ NMR spectrum of HDD exhibited signals that were consistent with those of BA and 2-hexylthiophene moieties as shown in Table 6. All signals in BA and 2-hexylthiophene were observed in the ${ }^{13} \mathrm{C}$ NMR spectrum of the synthesized product. The signals at $\delta 149.701,126.583$,
123.554, and $121.042 \mathrm{ppm}$ of HDD corresponded with the ones due to the thiophene ring of 2-hexylthiophene whereas the signals at $\delta 31.174,30.977,29.977,28.123,22.059$ and 13.938 ppm were consistent with hexyl chain of 2-hexylthiophene [41]. All the ${ }^{13} \mathrm{C}$ NMR spectral data of BA were also observed in the spectrum of HDD. However, minor differences were observed. 
Table 4 The ${ }^{1} \mathrm{H}$ NMR spectral data of the final dye HDD and its precursors BA and 2-hexylthiophene

\begin{tabular}{|c|c|c|c|c|c|}
\hline \multicolumn{3}{|c|}{ Assignment } & \multicolumn{3}{|c|}{$\delta(\mathrm{ppm})$} \\
\hline HDD & BA & $\begin{array}{l}\text { 2-hexylth- } \\
\text { iophene }\end{array}$ & HDD & BA & 2-hexylthiophene \\
\hline 1 & 1 & & 8.228 & 8.230 & \\
\hline 2 & 2 & & 8.162 & 8.169 & \\
\hline 3 & 3 & & 7.945 & 7.941 & \\
\hline \multirow[t]{2}{*}{4} & 4 & & 7.034 & 7.235 & \\
\hline & & A & & & 7.092 \\
\hline 5 & & $\mathrm{~B}$ & 6.933 & & 6.905 \\
\hline 6 & & $\mathrm{C}$ & 6.841 & & 6.770 \\
\hline 7 & & $\mathrm{D}$ & 2.797 & & 2.815 \\
\hline 8 & & $\mathrm{E}$ & 1.619 & & 1.670 \\
\hline 9 & & $\mathrm{~F}$ & 1.268 & & 1.360 \\
\hline 10 & & G & 1.246 & & 1.320 \\
\hline 11 & & $\mathrm{~J}$ & 1.226 & & 1.300 \\
\hline 12 & & $\mathrm{~K}$ & 0.870 & & 0.886 \\
\hline
\end{tabular}

The ${ }^{13} \mathrm{C}$ NMR spectrum of HDD exhibited a downfield shift for C-11 from $\delta 123.615$ of BA to $\delta 126.218 \mathrm{ppm}$. This could be attributable to the effect of bromide in BA which has a positive inductive effect, whereas the absence of bromide in HDD leaves C-11 with the effect of the carbonyl group at C-1. Another discrepancy was observed for $\mathrm{C}-13$ where the ${ }^{13} \mathrm{C}$ NMR spectrum of HDD showed the corresponding signal at $\delta 116-185 \mathrm{ppm}$ compared to $120.830 \mathrm{ppm}$ of BA. This is also due to the effect of $\mathrm{Br}$ as depicted in Table 6 and Fig. 11. The reference ${ }^{13} \mathrm{C}$ NMR spectral data were obtained from the database SDBS [41].

\section{Photocurrent density-Photovoltage measurement}

The synthesized dye HDD was put into test for DSSC application. The dye HDD was used in sensitization of
$\mathrm{TiO}_{2}$-coated photo-electrode and then a cell was assembled for photocurrent density-photovoltage $(J-V)$ measurement. Photovoltaic $J-V$ curve of the fabricated DSSC cell model is presented in Fig. 12, and the corresponding photovoltaic parameters are given in Table 7 . The performance of the fabricated cell was measured using solar simulator with AM 1.5 spectrum and output power of $100 \mathrm{~mW} / \mathrm{cm}^{2}$.

The photovoltaic parameters of the cell made by HDD dye are as presented in Table 7. The photovoltaic parameters taken and recorded in Table 7 include short-circuit current density $\left(J_{\mathrm{sc}}\right)$, open-circuit voltage $\left(V_{\mathrm{oc}}\right)$, fill factor (FF) and conversion efficiency ( $\eta)$. It was found that the fabricated DSSC showed $5.81 \%$ conversion efficiency. These was calculated using the obtained photovoltaic parameters as $V_{\mathrm{oc}}=0.65 \mathrm{~V}, J_{\mathrm{sc}}=0.0146 \mathrm{~A} / \mathrm{cm}^{2}$ and $\mathrm{FF}=0.612$. The value of short-circuit current density has increased by $0.0056 \mathrm{~A} /$ $\mathrm{cm}^{2}$ compared to the value of pure alizarin obtained previously using untreated semiconductor. Provided the value of $J_{\mathrm{sc}}$ is directly related to the absorption coefficient of the photosensitizer, the struggle to improve the $J_{\mathrm{sc}}$ value remains a focus of dye molecule. This may be attained through modification of the structure of molecule, introduction of the spacer group or anchoring group to the dye molecule. Therefore more studies are invited on modification of the reported molecule so as to enhance the performance of DSSC. The value of $V_{\text {oc }}$ reported previously when pure alizarin was used as dye sensitizer in DSSC was $0.75 \mathrm{~V}$ using untreated semiconductor and $0.80 \mathrm{~V}$ using treated semiconductor. The alizarin derivative dye HDD reported in this work displays the $V_{\text {oc }}$ of $0.65 \mathrm{~V}$. This shows the drop of $V_{\text {oc }}$ value by $0.1 \mathrm{~V}$ as compared to the previous report of pure alizarin. The theoretical results reported previously for the alizarin derivative dye HDD had the $V_{\text {oc }}$ value of $0.734 \mathrm{~V}$ [36]. The value shows close correlation with the experimental value by just small difference of $0.084 \mathrm{~V}$. Actually, one of the vital reason for the low efficiency of DSSCs is the low $V_{\text {oc }}$ output. To ensure better performance of the cell, the $V_{\mathrm{oc}}$ of
Fig. 9 The proton labeling of molecules a final dye HDD b 2-hexylthiophene [41]

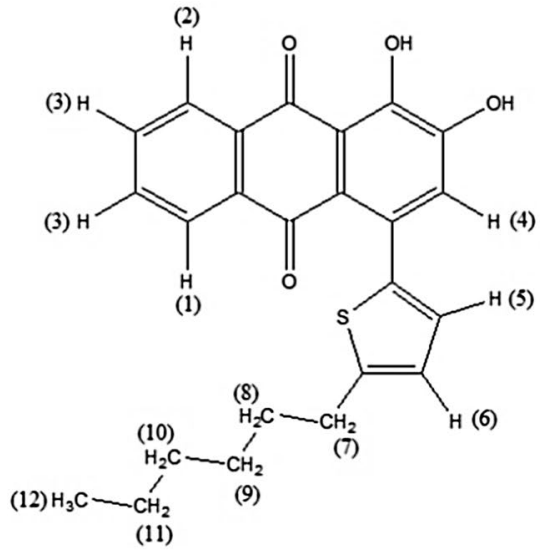

$\mathbf{a}$<smiles>[2H]c1sc(C([2H])([2H])C([2H])([2H])[2H])c(C)c1[2H]</smiles>

b 


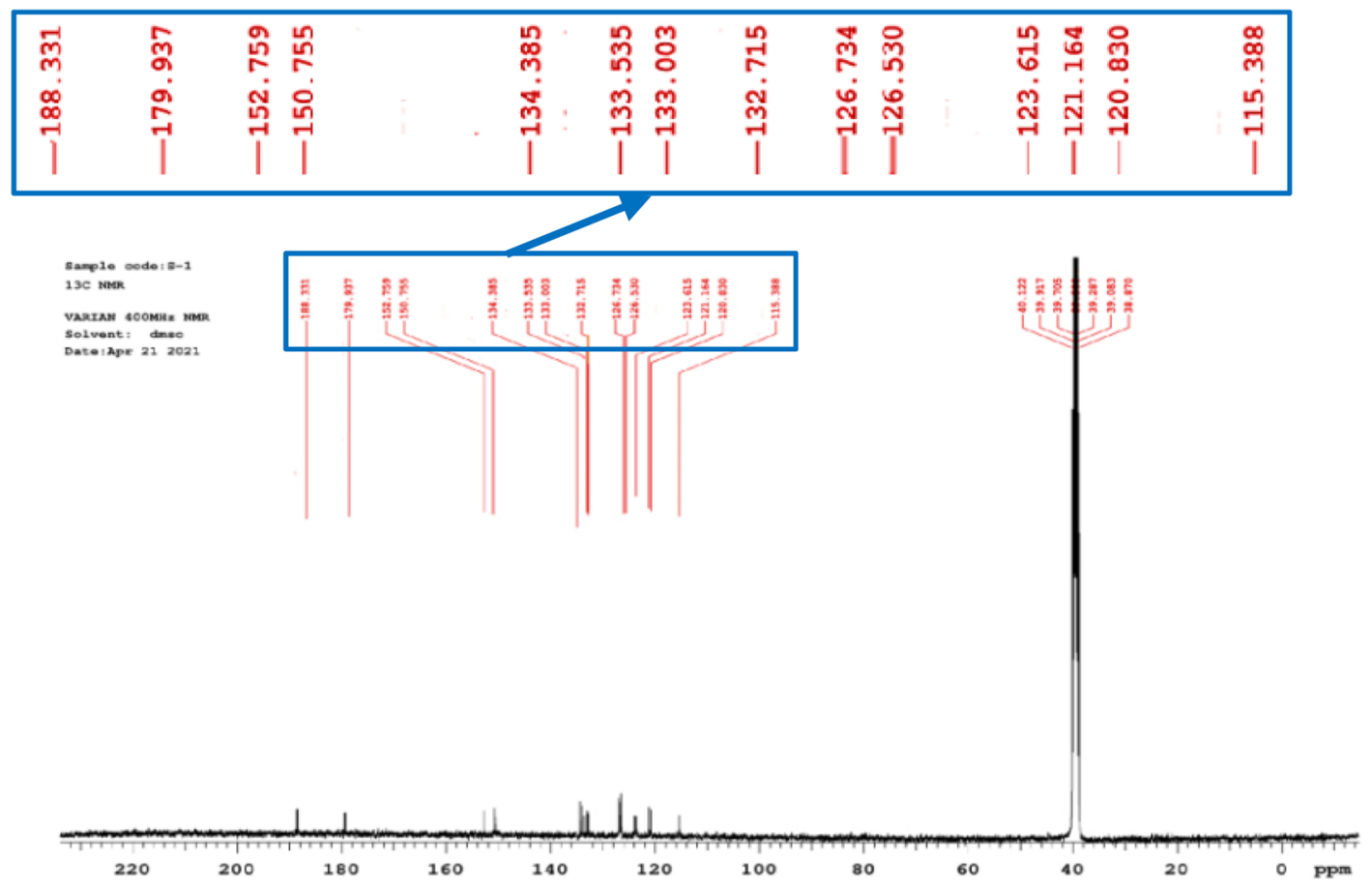

$\mathbf{a}$

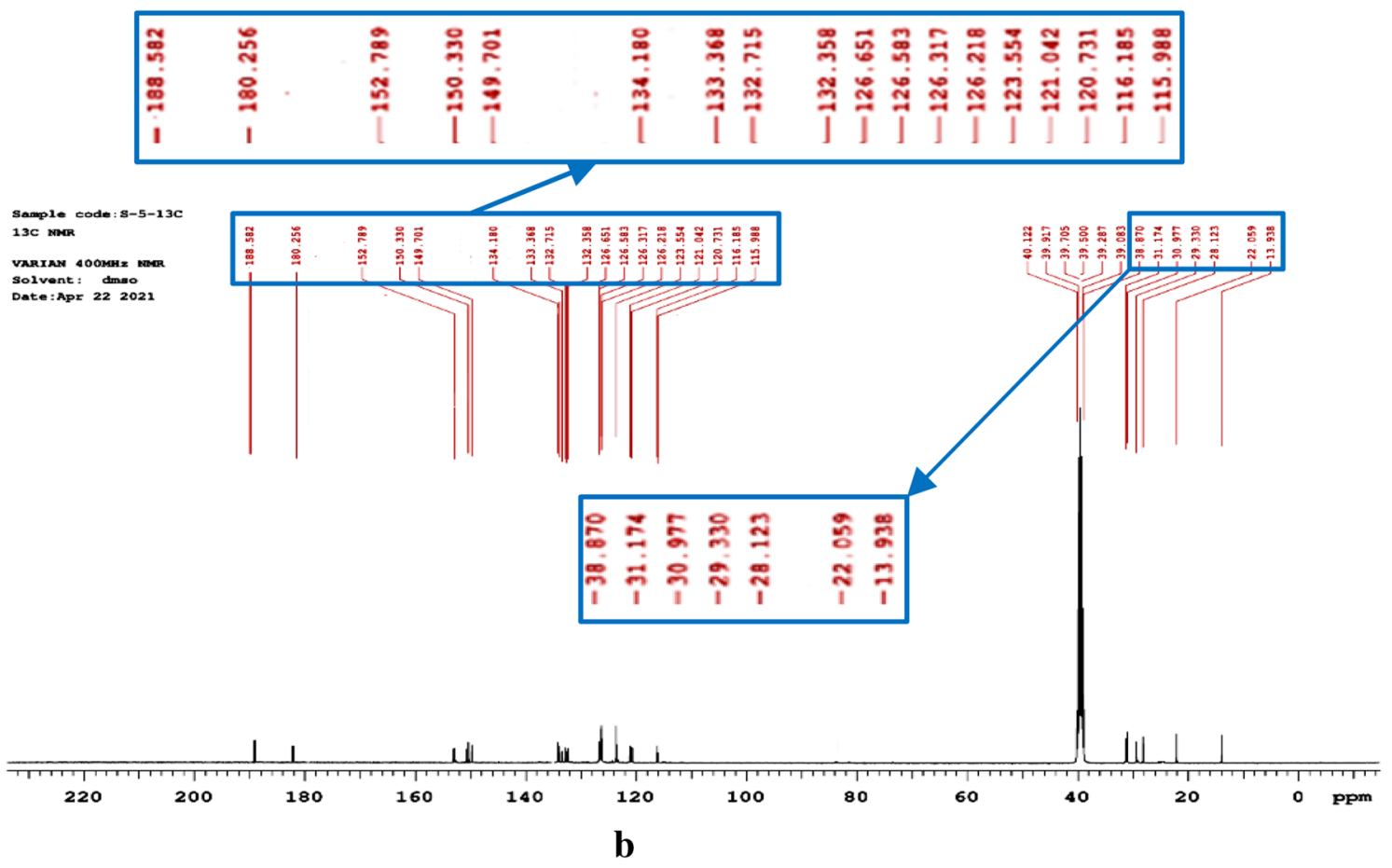

Fig. 10 The ${ }^{13} \mathrm{C}$ NMR for synthesized molecules a BA $\mathbf{b}$ final dye HDD

the cell should be as better as $0.8 \mathrm{~V}$ and above. As observed in this study, the value of $V_{\text {oc }}$ is only $0.65 \mathrm{~V}$; hence, more studies are encouraged to advance the value to about $0.8 \mathrm{~V}$. Mathematically, the increase in $V_{\text {oc }}$ to $0.8 \mathrm{~V}$ from the current 0.65 is equivalent to performance increase by $18.5 \%$. Since optimization of $V_{\mathrm{oc}}$ is principally possible through modification of semiconductor and electrolyte components of DSSC, the improvement may be considered in the same way. In this work the semiconductor used was untreated and yielded the specified value of $V_{\text {oc }}$ hence the first concern might be the 
Table 5 The ${ }^{13} \mathrm{C}$ NMR comparison table between HDD, BA and 2-hexylthiophene

\begin{tabular}{|c|c|c|c|}
\hline \multicolumn{2}{|c|}{ Assignment } & \multicolumn{2}{|l|}{$\delta(\mathrm{ppm})$} \\
\hline Alizarin & BA & Alizarin & BA \\
\hline 1 & 1 & 188.50 & 188.331 \\
\hline 2 & 2 & 180.20 & 178.937 \\
\hline 3 & 3 & 152.59 & 152.759 \\
\hline 4 & 4 & 150.63 & 150.755 \\
\hline 5 & 5 & 134.86 & 134.385 \\
\hline 6 & 6 & 133.77 & 133.533 \\
\hline 7 & 7 & 133.29 & 133.003 \\
\hline 8 & 8 & 126.54 & 132.715 \\
\hline 9 & 9 & 126.49 & 126.734 \\
\hline 10 & 10 & 126.23 & 126.530 \\
\hline 11 & 11 & 123.51 & 123.615 \\
\hline 12 & 12 & 120.95 & 121.164 \\
\hline 13 & 13 & 120.62 & 120.830 \\
\hline 14 & 14 & 115.94 & 115.388 \\
\hline
\end{tabular}

Table 6 The ${ }^{13} \mathrm{C}$ NMR comparison table between HDD, BA and 2-hexylthiophene

\begin{tabular}{|c|c|c|c|c|}
\hline \multicolumn{2}{|c|}{ Assignment } & \multicolumn{3}{|l|}{$\delta(\mathrm{ppm})$} \\
\hline BA & $\begin{array}{l}\text { 2-hexylthio- } \\
\text { phene }\end{array}$ & HDD & BA & 2-hexylthiophene \\
\hline 1 & & 188.582 & 188.331 & \\
\hline 2 & & 180.256 & 179.937 & \\
\hline 3 & & 152.789 & 152.759 & \\
\hline 4 & & 150.330 & 150.755 & \\
\hline & 1 & 149.701 & & 145.90 \\
\hline 5 & & 134.180 & 134.385 & \\
\hline 6 & & 133.368 & 133.533 & \\
\hline 7 & & 132.715 & 133.003 & \\
\hline 8 & & 132.358 & 132.715 & \\
\hline 9 & & 126.651 & 126.734 & \\
\hline & 2 & 126.583 & & 126.63 \\
\hline 10 & & 126.317 & 126.530 & \\
\hline 11 & & 126.218 & 123.615 & \\
\hline & 3 & 123.554 & & 123.88 \\
\hline & 4 & 121.042 & & 122.70 \\
\hline 12 & & 120.731 & 121.164 & \\
\hline 13 & & 116.185 & 120.830 & \\
\hline 14 & & 115.988 & 115.388 & \\
\hline & 5 & 31.174 & & 31.78 \\
\hline & 6 & 30.977 & & 31.59 \\
\hline & 7 & 29.977 & & 29.94 \\
\hline & 8 & 28.123 & & 28.81 \\
\hline & 9 & 22.159 & & 22.59 \\
\hline & 10 & 13.938 & & 14.07 \\
\hline
\end{tabular}

focus toward the use of treated semiconductor which will in turn increases the value of $V_{\mathrm{oc}}$ and eventually improves the conversion efficiency of the cell. Moreover, the improvement of $V_{\text {oc }}$ may be achieved by considering different kind of semiconductor like $\mathrm{ZnO}$ or considering the coupling of $\mathrm{ZnO}$ and $\mathrm{TiO}_{2}$.

The value of FF obtained for the dye HDD as shown in Table 7 is 0.612 . The previously reported values of FF for pure alizarin dye are 0.53 using untreated semiconductor and 0.58 using treated semiconductor. By considering the values of FF, there is an improvement in FF value by 0.082 using untreated $\mathrm{TiO}_{2}$ semiconductor. Moreover, when alizarin used as sensitizer in DSSC with untreated semiconductor it was recorded $3.57 \%$ conversion efficiency. Using $\mathrm{TiO}_{2}$ semiconductor treated with $\mathrm{TiCl}_{4}$, the alizarin sensitizer recorded the conversion efficiency of $5.12 \%$. In this work we report the conversion efficiency of $5.81 \%$ after modification of alizarin using 2-hexylthiophene and untreated semiconductor. This output signifies the improvement of conversion efficiency of alizarin-based dye by about $38 \%$ when using untreated semiconductor. Therefore a similar study using treated semiconductor is needed to investigate the improvement from the current $5.12 \%$ for pure alizarin. As shown in Eq. 1, conversion efficiency related directly with the photovoltaic properties of the cell as $V_{\mathrm{oc}}, J_{\mathrm{sc}}$ and FF. The improvement in conversion efficiency of the reported dye HDD was mostly influenced by the increase in the values of $J_{\text {sc }}$ and FF. As the matter of fact, more improvement of the dye HDD may be through improvement of $V_{\text {oc }}$ value to tally with the theoretical value. It should be noted here that all the reference data for pure alizarin dye were obtained in a work published by Manmeeta et al. in 2012 [31].

\section{Conclusion}

The dye molecule, HDD was successful synthesized using 5-hexyl-2-thiopheneboronic acid pinacol ester and BA which was previously prepared from the reaction of alizarin and bromine. The mass spectrometry, infrared spectroscopy and nuclear magnetic resonance spectroscopy were used to characterize and confirm the successful production of the targeted molecule. The final dye product was obtained as brownish-orange coloured solid and given the name 4-(5-hexylthiophen-2-yl)-1,2-dihydroxyanthracene9,10-dione correspondence to its structure in Fig. 1. The synthesized final dye was successfully tested for applicability in DSSC technology. Upon testing, the cell was generated the open-circuit voltage of $0.65 \mathrm{~V}$, short-circuit current density of $0.0146 \mathrm{~A} / \mathrm{cm}^{2}$ and fill factor of 0.612 . The use of the synthesized dye HDD in DSSC showed improvement in short-circuitcurrent density and fill factor compared to results from pure alizarin. Unfortunately, open-circuit 
Fig. 11 The carbon labelling of molecules a BA b 2-hexylthiophene

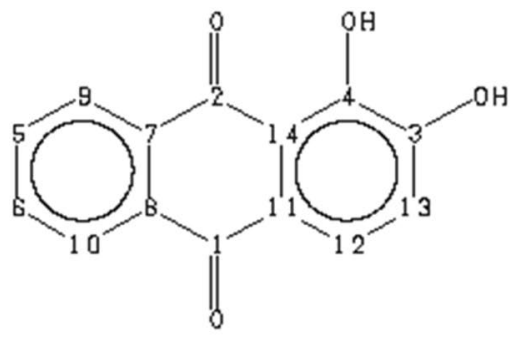

$\mathbf{a}$<smiles>[TeH]OBBSP[Te]1=NC=CS1</smiles>

b

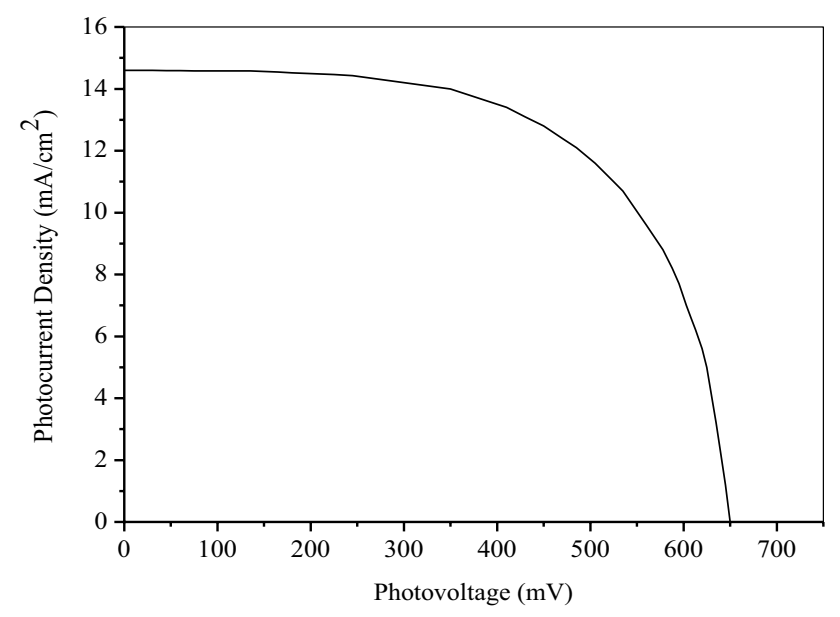

Fig. 12 The photovoltaic performance $(J-V$ curve) of the fabricated test cell

Table 7 The photovoltaic properties of synthesized dye HDD

\begin{tabular}{llll}
\hline Parameter & Value & \multicolumn{2}{l}{ Reference data } \\
\cline { 3 - 4 } & & Treated & Untreated \\
\hline$J_{\mathrm{sc}}$ & $0.0146 \mathrm{~A} / \mathrm{cm}^{2}$ & $0.0112 \mathrm{~A} / \mathrm{cm}^{2}$ & $0.009 \mathrm{~A} / \mathrm{cm}^{2}$ \\
$V_{\mathrm{oc}}$ & $0.65 \mathrm{~V}$ & $0.80 \mathrm{~V}$ & $0.75 \mathrm{~V}$ \\
$\mathrm{FF}$ & 0.612 & 0.58 & 0.53 \\
$P_{\text {in }}$ & $0.1 \mathrm{~W} / \mathrm{cm}^{2}$ & $0.1 \mathrm{~W} / \mathrm{cm}^{2}$ & $0.1 \mathrm{~W} / \mathrm{cm}^{2}$ \\
$\eta$ & $5.81 \%$ & $5.12 \%$ & $3.57 \%$ \\
\hline
\end{tabular}

voltage showed a drop hence more studies needed to improve this parameter. The conversion efficiency of the cell was found to be $5.81 \%$ under $100 \mathrm{~mW} / \mathrm{cm}^{2}$ solar simulations and untreated $\mathrm{TiO}_{2}$ semiconductor. The obtained conversion efficiency is equivalent to the increase by $38.6 \%$ from the previously reported efficiency of pure alizarin of $3.57 \%$ using untreated semiconductor. Worth to note here that the semiconductor used in this work was untreated and the efficiency output was beyond that of pure alizarin when treated semiconductor was used and yielded the conversion efficiency of $5.12 \%$. This result arise the need for more studies on the use of treated semiconductor with the reported dye molecule and analyse the performance output. The future studies are also arguably to concentrate on improving $V_{\text {oc }}$ which will in turn improve the performance of the cell. Moreover, the studies on synthesis of other alizarin derivative dyes theoretically reported in our previous works are encouraged $[4,36]$.

Acknowledgements The authors are appreciative to Professor B. Vijaya Kumar Naidu from the department of Materials Science and Nanotechnology of Yogivemana University, Kadapa, India for DSSC fabrication and conducting the $J-V$ characterization of the fabricated cell. We are also thankful to all specialists in DEV synthesis laboratory, ACCU laboratory and ALR laboratory in India for MS, IR and NMR characterization of synthesized molecules. More appreciation to Dr. Fortunatus Sunghwa of the University of Dar es Salaam, Tanzania, for his inputs in developing the synthetic routes for the synthesis of BA and HDD. Last but not least the authors are obliged to thank Dr. Laxmikanth Cherupally from the department of Physics, College of Natural and Mathematical Sciences, The University of Dodoma for his support to find the laboratories in India where the characterization of synthesized molecules BA and HDD were done even though it was a hard time during the high peak of COVID-19 in India where almost all the institutions were locked down.

\section{Declarations}

Conflict of interest The authors declare that they have no known competing financial interests or personal relationships that could have appeared to influence the work reported in this paper.

\section{References}

1. Breyer, C., Bogdanov, D., Gulagi, A., Aghahosseini, A., Barbosa, L.S.N.S., Koskinen, O., Barasa, M., Caldera, U., Afanasyeva, S., Child, M., Farfan, J., Vainikka, P.: On the role of solar photovoltaics in global energy transition scenarios. Prog. Photovolt. Res. Appl. 25, 727-745 (2017). https://doi.org/10.1002/pip.2885

2. Mohammadnezhad, M., Liu, M., Selopal, G.S., Navarro-Pardo, F., Wang, Z.M., Stansfield, B., Zhao, H., Lai, C.Y., Radu, D.R., Rosei, F.: Synthesis of highly efficient $\mathrm{Cu}_{2} \mathrm{ZnSnS}_{\mathrm{x}} \mathrm{Se}_{4-\mathrm{x}}$ (CZTSSe) nanosheet electrocatalyst for dye-sensitized solar cells. Electrochim. Acta. 340, 1-38 (2020). https://doi.org/10.1016/j.electacta. 2020.135954

3. Saini, R.K., Kadyan, P.S., Singh, J., Bhagwan, S., Singh, D.: Fabrication and photovoltaic characteristics of alizarin dye based DSSCs. Der. Pharma. Chem. 11, 43-48 (2019)

4. Abubakari, I., Babu, N.S., Vuai, S., Makangara, J.J.: Optical and photovoltaic properties of substituted alizarin dyes for dyesensitized solar cells application. Energy Sour. Part A: Recover. 
Util. Environ. Eff. 43, 2569-2582 (2021). https://doi.org/10. 1080/15567036.2020.1836083

5. Mohammadnezhad, M., Selopal, G.S., Wang, Z.M., Stansfield, B., Zhao, H., Rosei, F.: Role of carbon nanotubes to enhance the long-term stability of dye-sensitized solar cells. ACS Photonics 7, 653-664 (2020). https://doi.org/10.1021/acsphotonics.9b014 31

6. Michaels, H., Rinderle, M., Freitag, R., Benesperi, I., Edvinsson, T., Socher, R., Gagliardi, A., Freitag, M.: Dye-sensitized solar cells under ambient light powering machine learning: towards autonomous smart sensors for the internet of things. Chem. Sci. 11, 2895-2906 (2020). https://doi.org/10.1039/c9sc06145b

7. O’Regan, B., Grätzel, M.: A low-cost, high-efficiency solar cell based on dye-sensitized colloidal $\mathrm{TiO}_{2}$ films. Nature 353, 737-740 (1991). https://doi.org/10.1038/353737a0

8. Ananthi, N., Subathra, M.S.P., Emmanuel, S.C., Kumar, N.M.: Preparation and characterization of two dye-sensitized solar cells using Acalypha Godseffia and Epipremnum Aureum dyes as sensitizers. Energy Sour. Part A: Recover. Util. Environ. Eff. 42, 1662-1673 (2020). https://doi.org/10.1080/15567036.2019.16048 76

9. Ren, Y., Sun, D., Cao, Y., Tsao, H.N., Yuan, Y., Zakeeruddin, S.M., Wang, P., Grätzel, M.: A stable blue photosensitizer for color palette of dye-sensitized solar cells reaching $12.6 \%$ efficiency. J. Am. Chem. Soc. 140, 2405-2408 (2018). https://doi. org/10.1021/jacs.7b12348

10. Huang, J., Qian, X., Yang, J., Niu, Y., Xu, C., Hou, L.: Construction of Pt-free electrocatalysts based on hierarchical $\mathrm{CoS}_{2} / \mathrm{N}$-doped C@Co-WS 2 yolk-shell nano-polyhedrons for dye-sensitized solar cells. Electrochim. Acta. 340, 1-40 (2020). https://doi.org/10.1016/j.electacta.2020.135949

11. Reddy, A.C.K., Gurulakshmi, M., Susmitha, K., Raghavender, M., Thota, N., Subbaiah, Y.P.V.: A novel PEDOT:PSS/SWCNH bilayer thin film counter electrode for efficient dye-sensitized solar cells. J. Mater. Sci. Mater. Electron. 31, 4752-4760 (2020). https://doi.org/10.1007/s10854-020-03032-3

12. Kakiag, E.K., Aoyama, Y., Yano, T., Oya, K., Fujisawa, J.I., Hanaya, M.: Highly-efficient dye-sensitized solar cells with collaborative sensitization by silyl-anchor and carboxy-anchor dyes. Chem. Commun. 51, 15894-15897 (2015). https://doi.org/10. 1039/c5cc06759f

13. Wang, M., Grätzel, C., Zakeeruddin, S.M., Grätzel, M.: Recent developments in redox electrolytes for dye-sensitized solar cells. Energy. Environ. Sci. 5, 9394-9405 (2012)

14. Yin, J.F., Velayudham, M., Bhattacharya, D., Lin, H.C., Lu, K.L.: Structure optimization of ruthenium photosensitizers for efficient dye-sensitized solar cells: a goal toward a "bright" future. Coord. Chem. Rev. 256, 3008-3035 (2012). https://doi.org/10.1016/j.ccr. 2012.06.022

15. Xu, T., Kong, D., Tang, H., Qin, X., Li, X., Gurung, A., Kou, K., Chen, L., Qiao, Q., Huang, W.: Transparent $\mathrm{MoS}_{2} / \mathrm{PEDOT}$ composite counter electrodes for bifacial dye-sensitized solar cells. ACS Omega 5, 8687-8696 (2020). https://doi.org/10.1021/acsom ega.0c00175

16. Sangiorgi, N., Sangiorgi, A., Dessì, A., Zani, L., Calamante, M., Reginato, G., Mordini, A., Sanson, A.: Improving the efficiency of thin-film fiber-shaped dye-sensitized solar cells by using organic sensitizers. Sol. Energy. Mater. Sol. Cells. 204, 1-8 (2020). https://doi.org/10.1016/j.solmat.2019.110209

17. Bourass, M., Touimi, B.A., Hamidi, M., Benzakour, M., Mcharfi, M., Sfaira, M., Serein-Spirau, F., Lère-Porte, J.P., Sotiropoulos, J.M., Bouzzine, S.M., Bouachrine, M.: DFT theoretical investigations of $\pi$-conjugated molecules based on thienopyrazine and different acceptor moieties for organic photovoltaic cells. J. Saudi. Chem. Soc. 20, S415-S425 (2016). https://doi.org/10.1016/j.jscs. 2013.01.003
18. Li, X.G., Liu, Y.W., Huang, M.R., Peng, S., Gong, L.Z., Moloney, M.G.: Simple efficient synthesis of strongly luminescent polypyrene with intrinsic conductivity and high carbon yield by chemical oxidative polymerization of pyrene. Chem. A Eur. J. 16, 4803-4813 (2010). https://doi.org/10.1002/chem.200902621

19. Maddah, H.A., Berry, V., Behura, S.K.: Biomolecular photosensitizers for dye-sensitized solar cells: recent developments and critical insights. Renew. Sustain. Energy. Rev. 121, 1-25 (2020). https://doi.org/10.1016/j.rser.2019.109678

20. Gong, J., Sumathy, K., Qiao, Q., Zhou, Z.: Review on dye-sensitized solar cells (DSSCs): advanced techniques and research trends. Renew. Sustain. Energy. Rev. 68, 234-246 (2017). https:// doi.org/10.1016/j.rser.2016.09.097

21. Błaszczyk, A.: Strategies to improve the performance of metalfree dye-sensitized solar cells. Dye Pigment. 149, 707-718 (2018). https://doi.org/10.1016/j.dyepig.2017.11.045

22. Ye, M., Wen, X., Wang, M., Iocozzia, J., Zhang, N., Lin, C., Lin, Z.: Recent advances in dye-sensitized solar cells: from photoanodes, sensitizers and electrolytes to counter electrodes. Mater. Today. 18, 155-162 (2015). https://doi.org/10.1016/j.mattod.2014. 09.001

23. Beula, R.J., Suganthi, D., Abiram, A.: $\mathrm{TiO}_{2}$ photo-electrode with gold capping for improved observation in dye-sensitized solar cell. Appl. Phys. A Mater. Sci. Process. 126, 1-8 (2020). https://doi. org/10.1007/s00339-020-3394-y

24. Chen, M., Wang, G.C., Yang, W.Q., Yuan, Z.Y., Qian, X., Xu, J.Q., Huang, Z.Y., Ding, A.X.: Enhanced synergetic catalytic effect of $\mathrm{Mo}_{2} \mathrm{C} / \mathrm{NCNTs} @$ Co heterostructures in dye-sensitized solar cells: fine-tuned energy level alignment and efficient charge transfer behavior. ACS. Appl. Mater. Interfaces. 11, 42156-42171 (2019). https://doi.org/10.1021/acsami.9b14316

25. Al-Alwani, M.A.M., Ludin, N.A., Mohamad, A.B., Kadhum, A.A.H., Mukhlus, A.: Application of dyes extracted from Alternanthera dentata leaves and Musa acuminata bracts as natural sensitizers for dye-sensitized solar cells. Spectrochim. Acta: Part A Mol Biomol. Spectrosc. 192, 487-498 (2018). https://doi.org/ 10.1016/j.saa.2017.11.018

26. Babu, D.D., Naik, P., Keremane, K.S.: A simple D-A- $\pi$-A configured carbazole based dye as an active photo-sensitizer: a comparative investigation on different parameters of cell. J. Mol. Liq. 310, 1-8 (2020). https://doi.org/10.1016/j.molliq.2020.113189

27. Naik, P., Elmorsy, M.R., Su, R., Babu, D.D., El-Shafei, A., Adhikari, A.V.: New carbazole based metal-free organic dyes with D-П-A-П-A architecture for DSSCs: synthesis, theoretical and cell performance studies. Sol. Energy. 153, 600-610 (2017). https:// doi.org/10.1016/j.solener.2017.05.088

28. Keawin, T., Tarsang, R., Sirithip, K., Prachumrak, N., Sudyoadsuk, T., Namuangruk, S., Roncali, J., Kungwan, N., Promarak, V., Jungsuttiwong, S.: Anchoring number-performance relationship of zinc-porphyrin sensitizers for dye-sensitized solar cells: a combined experimental and theoretical study. Dye. Pigment. 136, 697-706 (2017). https://doi.org/10.1016/j.dyepig.2016.09.035

29. Zhang, L., Yang, X., Wang, W., Gurzadyan, G.G., Li, J., Li, X., An, J., Yu, Z., Wang, H., Cai, B., Hagfeldt, A., Sun, L.: $13.6 \%$ Efficient organic dye-sensitized solar cells by minimizing energy losses of the excited state. ACS Energy. Lett. 4, 943-951 (2019). https://doi.org/10.1021/acsenergylett.9b00141

30. Mathew, S., Yella, A., Gao, P., Humphry-Baker, R., Curchod, B.F.E., Ashari-Astani, N., Tavernelli, I., Rothlisberger, U., Nazeeruddin, M.K., Grätzel, M.: Dye-sensitized solar cells with $13 \%$ efficiency achieved through the molecular engineering of porphyrin sensitizers. Nat. Chem. 6, 242-247 (2014). https://doi. org/10.1038/nchem.1861

31. Manmeeta, S.D., Sharma, G.D., Roy, M.S.: Improved performance of oxidized alizarin based quasi solid state dye sensitized solar cell by surface treatment. Res. J. Chem. Sci. (ACS) 2, 61-71 (2012) 
32. Jen, M., Lee, S., Jeon, K., Hussain, S., Pang, Y.: Ultrafast intramolecular proton transfer of alizarin investigated by femtosecond stimulated raman spectroscopy. J. Phys. Chem. B. 121, 4129-4136 (2017). https://doi.org/10.1021/acs.jpcb.6b12408

33. Buchanan, R.: A Weaver's garden: growing plants for natural dyes and fibers. Dover Publications Inc. (1999)

34. Singh, H.B., Bharati, K.A.: Mordants and their applications: handbook of natural dyes and pigments. Woodhead Publishing India, New Delhi (2014)

35. Sun, C., Li, Y., Han, J., Cao, B., Yin, H., Shi, Y.: Enhanced photoelectrical properties of alizarin-based natural dye via structure modulation. Sol. Energy. 185, 315-323 (2019). https://doi.org/10. 1016/j.solener.2019.04.078

36. Abubakari, I., Babu, S., Vuai, S., Makangara, J.J.: 2-Hexylthiophene-substituted alizarin-based (D- $\pi-A)$ organic dyes for dyesensitized solar cell applications: density functional theory and UV-Vis studies. J. Chem. Res. 45, 13-20 (2021). https://doi.org/ $10.1177 / 1747519820922450$

37. Matsuyama, S., Kinugasa, S., Tanabe, K., Tamura T.: Spectral database for organic compounds, (SDBS). National institute of advanced industrial science and technology (AIST). https://sdbs. db.aist.go.jp/sdbs/cgi-bin/direct_frame_top.cgi (1999). Accessed 26 August 2021

38. Schoffstall, A. M., Gaddis. B. A. and Druelinger. M. L.: Microscale and miniscale organic chemistry laboratory experiment. McGraw-Hill. (2004)
39. Matsuyama, S., Kinugasa, S., Tanabe, K., Tamura T.: Spectral database for organic compounds (SDBS). National institute of advanced industrial science and technology (AIST). https://sdbs. db.aist.go.jp/sdbs/cgi-bin/direct_frame_top.cgi (2013). Accessed 26 August 2021

40. Saito, T., Yamaji, T., Hayamizu, K., Yanagisawa, M., Yamamoto O.: Spectral database for organic compounds (SDBS). National institute of advanced industrial science and technology (AIST). https://sdbs.db.aist.go.jp/sdbs/cgi-bin/direct_frame_top.cgi (1999). Accessed 26 August 2021

41. Saito, T., Yamaji, T., Hayamizu, K., Yanagisawa, M. Yamamoto O.: Spectral database for organic compounds (SDBS). National institute of advanced industrial science and technology (AIST). https://sdbs.db.aist.go.jp/sdbs/cgi-bin/direct_frame_top.cgi (2013). Accessed 26 August 2021.

Publisher's Note Springer Nature remains neutral with regard to jurisdictional claims in published maps and institutional affiliations. 